\title{
Kiev ex-libris school as a xylography traditions keeper in printmaking of modern Ukraine
}

\begin{abstract}
The article is dedicated to Kiev ex-libris school role (EL) in modern Ukrainian printmaking. The loss process by a bookplate of utilitarian, applied functions and its transformation into an independent work of art, collectors' object of interest with an appreciated art value is described. The ex-libris schools formed in the first quarter of the 21st century are emphasized, the main trends of the bookplate development predominant centers are defined (Kiev, Lvov, Odessa, Luhansk). Printmaking techniques, typical for a particular ex-libris school, are marked. Kiev bookplate school, as one of the leading centers for the classical xylography traditions preservation, is underlined. The most significant masters, working in these techniques, are presented, the technological process evolution is indicated and its main reasons are emphasized. The problem of opposition between the old and new in the art of printmaking is touched upon by example of classical techniques and gathering momentum computer graphics (CGA) coexistence.
\end{abstract}

\section{KEY WORDS}

Printmaking, xylography, chalcography, ex-libris, woof cut, lino cut

\author{
Julia Romanenkova ${ }^{1}$ (1) \\ Anna Paliychuk ${ }^{1}$ \\ Vadym Mykhalchuk ${ }^{2}$
${ }^{1}$ Kiev Municipal Academy of Circus and Performing Arts, Department of Music Art, Kiev, Ukraine Arts Management, Department of Culturology and Art-Management, Kiev, Ukraine \\ ${ }^{2}$ National Academy of Culture and
}

Corresponding author:

Julia Romanenkova

e-mail:

20romanenkova20@gmail.com

\section{Introduction}

On the cusp of the XX and XXI centuries there are trends that are truly considered to be the main ones for these art types emerging in the field of Ukrainian printmaking and graphic design. The first trend lies in a rather rapid movement towards a clear line erasing between the graphic arts and graphic design, the second one - in old traditions and new developments in graphic arts, primarily is in printmaking, that far from always lead to the organic synthesis formation, but more often - to the displacement of one by another. In both cases the computer graphic arts (CGA) popularization in recent years have become the most pronounced reason, to the arsenal of which the artists increasingly resort to, abandoning the means of printmaking classical techniques artistic expression. And this is most clearly manifested in the ex-libris field that has received a new step of its development since the 1990s. If for a very long time from the moment of its appearance and existence, beginning in the 16th century, the bookplate had been performing a strictly applied function, then in the last few decades it rapidly went beyond the utilitarian role and acquired aesthetic qualities. This process ended with the fact the bookplate almost completely separated from the book nature, having lost its dependence on it and turned into an independent work of art. In all countries of the world, where ex-libris has an existence history and demand, this process took place, but the name is slightly different in chronological framework and time. In the USA and Asian countries, the bookplate follows a separate evolutionary path, not having such popularity there and not being so in demand among collectors and graphic arts admires, as in the countries of Europe 
and the post-Soviet ones. In Europe, back in 1966 year, FISAE, the International Federation of Bookplate Lovers, was founded, whose history began in Germany, as well as the history of the bookplate itself, the first samples of which were also published in Germany, Austria, Belgium, Great Britain, the Netherlands, Poland, Russia, Slovakia, the Czech Republic, Ukraine can be called to be among the countries, where the bookplate is especially popular, that is expressed in the presence there a large number of highly professional masters, many collectors, specialized museums, often holding competitions and exhibitions (Romanenkova, 2015a). In each of the countries the competition and exhibition process has its own specificities: the competitions that have become constant or at least frequent, somewhere dominate (Ruse ex-libris competition in 2019, 2020, the one in Sint-Niklaas, 2019, ex-libris competition in Bristol in 2020, etc. are among the recent examples), specialized publications dedicated to the bookplate are printed somewhere (Belgium «Graphia», Portugal - «Encyclopaedia Bio-Bibliographical of the Art of the Contemporary Ex-Libris», etc.), some of the countries can boast of relevant societies apart FISAE ((Great Britain - «Society of Wood Engravers», «Royal Society of Painter-Printmakers»; Germany - «Deutschen Exlibris-Gesellschaft»; Italy - «Associazione Italiana Ex Libris»; Russia - «Russian MSC Ex-libris Association (Moscow book-lovers community)», St. Petersburg «Ex-libris Collectors Club»; Ukraine - «Ukrainian Ex-libris Club»; France - «Association Française pour la Connaissance de I'Ex Libris», «L'Ex Li bris Française», etc)) (Romanenkova, Bratus \& Kuzmenko, 2021). Competitions organizing and societies creating process has been continuous for the last half of the century, but in Ukraine it has intensified, having given an opportunity to talk about modern Ukrainian ex-libris school birth and a new landmark in its history only since the early 1990s, when the country gained independence. It was from this time the artists overcame the «Iron Curtain», became mobile, got the opportunity to join the international artistic process and become the part of world art field.

\section{Literature review}

Precisely because of a rather clear divide between the classic bookplate history and its modern «art biography», the ex-libris problem bibliography consists of two research categories - ex-libris works until the 1990s and ones on Ukraine purely modern bookplate from the period of its independence. The first category is represented mainly by unrelated works on the ex-libris history certain aspects from the 16th century: these are researches by N. Belichko, Y. Berdychevsky (Berdychevsky, 1977), P. Vyunik, the Ukrainian ex-libris club chairman P. Nesterenko (Nesterenko, 2002; Nesterenko, 2020), O. Lamonova. Only one dissertation was defended, dedicated to Ukraine bookplate from its appearance to the first half of the XX century, the author of which was the same P.
Nesterenko, who later published several monographies on the same topic. This testifies to the lack of complex scientific studies on Ukrainian ex-libris topic, and there are still known to be prospects for research work.

In very rare cases it is possible to find in the literature sources that would illustrate the bookplate creating techniques (Nesterenko, 2002) - there are very few practicing artists among the theoretical developments authors who are well-versed in the technological process intricacies (Kamenetskaya, 2019).

The second sources category covers Ukraine ex-libris of the last three decades. In the bulk of works there are also the ones dedicated to individuals; developments on certain topical issues of this period bookplate evolution: articles by J. Kamenetskaya, the author of still the only dissertation on modern Ukrainian bookplate (Kamenetskaya, 2019), V. Mikhalchuk (Mikhalchuk, 2014a; Mikhalchuk, 2014b), J. Romanenkova (Romanenkova, 1999a; Romanenkova, 1999b; Romanenkova, 2003; Romanenkova, 2015a; Romanenkova, 2015b; Romanenkova et al., 2021; Romanenkova, 2021), T. Safonova (Safonova, 2011), V. Tupik (Tupik, 2017); exhibitions reviews, individual collections characteristics. Ukrainian researchers' publications about country bookplate, that go beyond it, should be especially pointed out, - this type of prints popularization has become one of the clearest trends in modern graphic art in Ukraine. There are many foreign critics and collectors, and sometimes the artists themselves, Ukrainian ex-librists' works connoisseurs in the bibliography and sources of authorship. Patrons appeared, both in Ukraine and in the other countries, supporting talented masters' development, sponsoring exhibitions, publishing books, catalogs (it is S. Brodovich in Ukraine, whose publishing house has issued a lot of monographic studies about modern Ukrainian masters of a bookplate, for outside the country - a Belgian L. Van Den Briele, an Italian M. de Philippis, a Portuguese A. M. da Mota Miranda, etc.)

\section{Bookplate schools in modern art of Ukraine}

In Ukraine bookplate wide diversity of the last three decades there is a tendency to detach several main centers of its development and popularization that allows us to speak of the independent schools formation, represented by interesting, highly professional masters (Romanenkova, 2021). Each of these centers has its own stylistic features, characteristics collection that allows one or another artist to be referred to a particular school, based not only on the geographical aspect. It is not infrequent that certain deserving masters can be highlighted, outside the school, because noticing the ex-librists among the artists range alongside them gets failure, but they 
themselves are so significant and remarkable for the exlibris history that become independent elements in the picture. One example is Konstantin Kalinovich - a master from Luhansk, where the school as such was not formed, however, this artist became one of the most significant for understanding the modern Ukrainian bookplate and printmaking in general, having a huge competitive and exhibition experience, being in demand among the most famous collectors, having become recognizable for the unique author's style and technique. Andrey Khvorost, representing Kirovograd, Miroslav Korol from Ivano-Frankovsk, Orest Krivoruchko from Chernovtsy, Vasiliy Leonenko from Chernigov, Boris Romanov from Severodonetsk, Vladimir Lomaka from Sumy, the famous Odessa resident David Bekker, and others stand out as well. It would be inappropriate to make any mention of them, because their works are peculiar to general picture of the development and compilation of Ukraine bookplate general stylistics at the turn of the XXI century.

However, one may truly talk of independent ex-libris schools in several art centers of Ukraine, each of which is marked by a large number of ex-librists. First of all, this is the Lvov school (with its main representatives in the person of Sergey Ivanov, Sergey Khrapov, Oleg Denisenko, Oleg Andreev, Igor Bodnar, Artem Bulka, Valeriy Demyanishin, Boris Drobotyuk, Olga Fedoruk, Orest Gelitovich, Igor Yanovich, Yaroslav Kachmar, Yuriy Kokh, Yevgeniy Kozanevich, and others), the Kharkov school (represented by Vadim Aleksandrov, Viktor Igumentsev, Alla Khmel, and others) and, of course, the capital's art center Kiev bookplate school. Printmaking techniques, where ex-librises are created, can be called one of the most significant features that determine the characteristics of a particular school. Each school has its certain preferences, they might most be clearly defined in the Lvov school - chalcography techniques have been dominating there for a long time, at most it is either pure etching, which is used without mixing with other techniques (C3), or several techniques complex combinations, whose tooling is synthesized in one sheet: etching, mezzotint, aquatint, soft ground etching (C3C5C7). Lvov bookplates colour range is often quite monochrome and black-and-white compositions are not infrequent. Although masterfully executed multicolour etchings can be also found ( $\mathrm{V}$. Demyanishin).

\section{Kiev ex-libris school at the cusp of the $X X$ and $X X I$ centuries}

But the capital school is characterized by its technical preferences polyvector nature. Tamara Balenko, Sergey and Anatoly Burtovoy, Arkady Faktorovich, Victor Romanenkov, Yuriy Galitsyn, Stanislav Gavrilyuk, Konstantin Kozlovsky, Vasiliy Lopata, Nikolay Stratilat, Aleksandr Savich, the Kharuk brothers, Vladimir Taran, the Pugachevsky creative dynasty, Konstantin Antioukhin, Yulia Kamenetskaya, Ruslan Agirba, Aleksandr Savich, Ruslan Vigovsky - only a small part of the masters, representing Kiev school in the international art field. There are blackand-white and colour xylography, lino cut, lithography, congreve printing (blind), etching, mezzotint, aquatint, soft ground etching, copper and steel engraving. Many artists have a shot at both xylography and chalcography techniques. Bent for computer graphic arts, as one of the more and more popular in the bookplate creation, has become the main trend in the last few years. It is notable this choice is made most often by the representatives of the artists' young generation (Y. Kamenetskaya), more rarely - by the middle one (R. Vigovsky) (Figure 1), while the older generation adheres to classical prints techniques, not replacing them with CGA tooling.

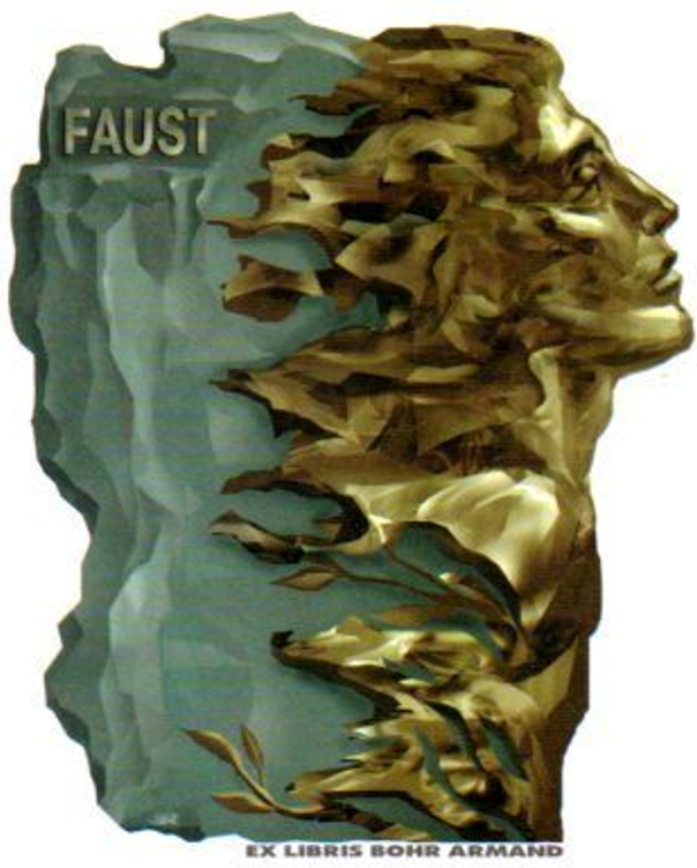

» Figure 1: Vigovsky R. EL Armand Bohr. CGA. 2009

This speaks not only of certain tendencies in techniques choice within Kiev ex-libris school, but also gives emphasis to another trend - the bookplate gradation probability from book's elements, book graphic arts' segments to the field of computer design, that increasingly crosses critics' lips. However, it will be yet only the one of the events development options if, as time progressed, the CGA more and more displaces academic prints with all the variety of its techniques. Unfortunately, such a possibility exists because academic classical techniques with all their complexity are less often accessible to artists, young masters infrequently are able to use them professionally. Moreover, the professional art education degradation level does not aid classical techniques preservation and development. Another reason for the academic printmaking techniques risk of disappearance is the economic aspect, i.e. materials' high price. Lino 
cut remains among the still more accessible one, lithography, as before, is a rather expensive pleasure, therefore, it cannot be referred to the favorites in the list of techniques used by bookplate masters. Wood cut might typify the evolution of technological aspect in xylography. Quite a lot of stages have passed from the academic interpretation to the technique modern reading, both the materials and icon obtaining process peculiarities have being changed. If initially only certain wood types were used to create engravings, using the xylography technique (woof cut is more often known for its solidity), then in recent decades it is increasingly possible to meet with engravings on cardboard, organic glass, and plastic. Various plastic types have been used for a long time as the most popular and accostable synthetic substitute for wood, which is expensive due to its naturalness. It can be of different thickness, up to very thin, not much thicker than heavy paper. Coated with black colour and used as a base, it allows to attain a soft, flowing stroke. Artists as well use organic glass to create bookplates (e.g., N. Stratilat often resorts to it), which cannot be considered an equivalent substitute for wood due to a different structure that does not give the velvety stroke that is possible, when engraving is created on a wood base. Cardboard, which is also used as a basis for printing form creating, cannot be absolutely accepted as wooden boards substitute; working on it leads to the destruction of xylographic sheet true creating process understanding. While copying, the cardboard gets soaked quite quickly, absorbing the paint, goes through a limited circulation and absolutely cannot give a clear, finely-honed picture, a stroke of pinpoint precision, which is possible for wood or plastic. Due to its availability, cardboard is often used in higher educational establishments, when students-artists learn the technology ropes. But this is particular what should not be allowed - getting used to bad material from the very beginning leads to the fact the artist too often allows himself afterwards a compromise in technology, artificially simplifying printing form creating process that results in a loss of icon quality. Wood cut, especially on hard boxwood, is far from being possible for every master, even physically. This job requires a well-positioned, firm hand and a perfect eye.

Plastic has become an equivalent but cheaper synthetic substitute for wooden forms. It is often used by modern ex-librists of the Kiev school. Quality materials have always been a significant formula for future work success. The masters of the old school, classical training still operate today according to this principle. Unfortunately, the younger generation inclines to simplify the process, that compromise the quality of works. In addition to the basis, on which the printed form for xylography is created, paper has always been of no small importance - of certain solidity, textures, shade. Today, despite the widest range of paper types used for printmaking, more and more masters, who try to preserve the xylography classic traditions making paper by hand, appear. The Kiev artist of
Georgian origin R. Agirba began to use handmade paper, following the Luhansk graphic artist K. Kalinovich, known in many world countries for his author's books, created completely by hand. He, like many masters representing Kiev bookplate school, tries his hand at both xylography and chalcography techniques. His earlier ex-librises were created mainly in the xylography technique - they were plastic engravings, both black-and-white and in several boards, polychrome (Figure 2). The works created in this particular technique have brought the fame and prestigious awards to the master at more than 20 international exhibitions. Recent years the master has given preference to etching, making reprints on handmade paper, thus, demonstrating one of the main Kiev school trends - artists' experiments in different techniques, as opposed to, for example, Lvov ones, who traditionally prefer chalcography.

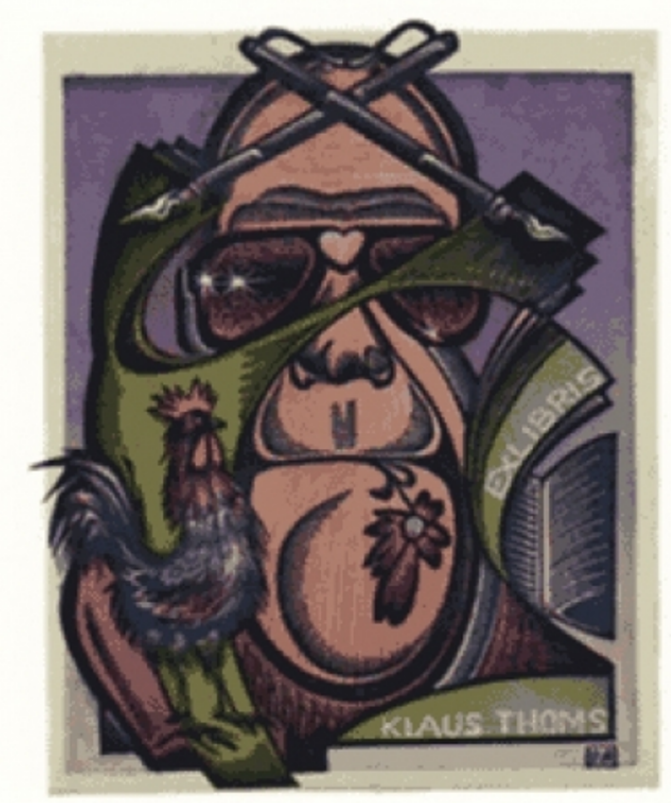

» Figure 2: Agirba R. EL Klaus Thoms. X6/6. 1996

Many Kiev ex-librists such as, for instance, V. Romanenkov, V. Taran, Y. Galitsyn, A. Savich, V. Lopata, and others work in the same technique. Sometimes xylography tooling and congreve (blind stamping) synthesis experiments can be observed, in some cases gilding comes into use, i.e. xylography is enriched with printmaking methods and means ( $V$. Romanenkov). The representatives' of the Pugachevsky dynasty creative works are characteristic by many criteria, they are definitely can be called the xylography traditions keepers in the modern Kiev ex-libris. Arkady and Gennady Pugachevskys - father and son - are two generations representatives, each of which has become a quintessence kind of the most remarkable features inherent in both generations. This is manifested both in the technique choice and images character, which each of the masters stylizes in his own way. 
Their creative biographies are quite demonstrative in one more aspect: they are «unofficial» prominent representatives, one can say - of Ukraine graphic arts underground layer, in particular, of the Kiev school. Neither Arkady nor Gennady are included in the official art community - they are not members of the National Union of Artists of Ukraine, do not have awards received within the country, in actual fact do not exhibit within Ukraine. Arkady Pugachevsky (who died in 2021), like his son, had only a few personal exhibitions in Ukraine in the early 1990s. (1990 - Lvov, 1991, 1992, 1995 Kiev), i.e. at the beginning of Ukrainian bookplate renaissance, and it was he who was one of this process originators. But at the same time he was a member of «Deutschen Exlibris-Gesellschaft» (Germany) and «Society of Wood Engravers» (Great Britain), winner of grand prix, first prizes, special prizes at dozens of international exhibitions in Belgium (1993, 1995, 1996, 1997, 1999), Poland (1992, 1993, 1994, 1995, 1996, 1997, 2001, 2003), Italy (1994), Japan (1998), Lithuania (1993, 1994), the USA (2001, 2006). Master's works posthumous exhibition was also being prepared outside his own country - his talent connoisseurs in China were the first who decided to pay respect to the artist memory.

Gennady Pugachevsky is also not included in the artists community recognized in his country, well-treated by the authorities from art. He did not even receive a specialized education, having left the institute's walls without completing his studies. But it did not prevent him (rather - helped forward) from receiving the Associate Fellowship of the Royal Society of Painter-Printmakers (Great Britain) status and became the Society of Wood Engravers (Great Britain) member. The master received the most significant awards at prestigious exhibitions and bookplates and applied graphics competitions in Spain (1992), Lithuania (1993, 1997), the Netherlands (1993, 1995, 1997, 1998), Poland (1993, 1994, 1995, 1996, 2001), Denmark (1994), the USA (2001, 2006), France (1997), Italy (1994). It is thanks primarily to $A$. and G. Pugachevsky the Ukrainian bookplate was recognized outside the country. They are long-time participants in the FISAE congresses, it was they who organized bookplate first international exhibition-competitions in Ukraine $(1993,1994)$ in the cooperation with the president and several members of the Ukrainian ex-libris club founded in the 1990s.

Arkady Pugachevsky had been working in plastic engraving technique for many years and his hobby was not limited to ex-libris. His sheets could be either black-andwhite, with the stylization maximum degree, conventionality and closeness to the sign system, or coloured. And if the artist's prints can be rather large sized (Figure 3), then the ex-libris was usually quite chamber (Figure 4). Pugachevsky's Sr. graphics' technique can be called an etalon - his engraving tool gave a birth to compositions of amazing polish, the highest level of professionalism.

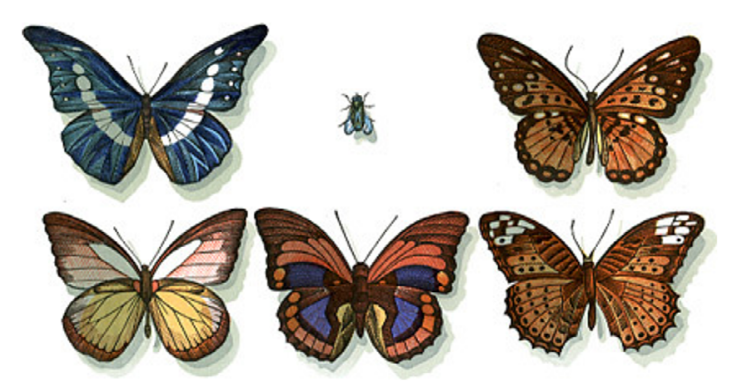

» Figure 3: Pugachevsky A. «Collection». X6. 2002

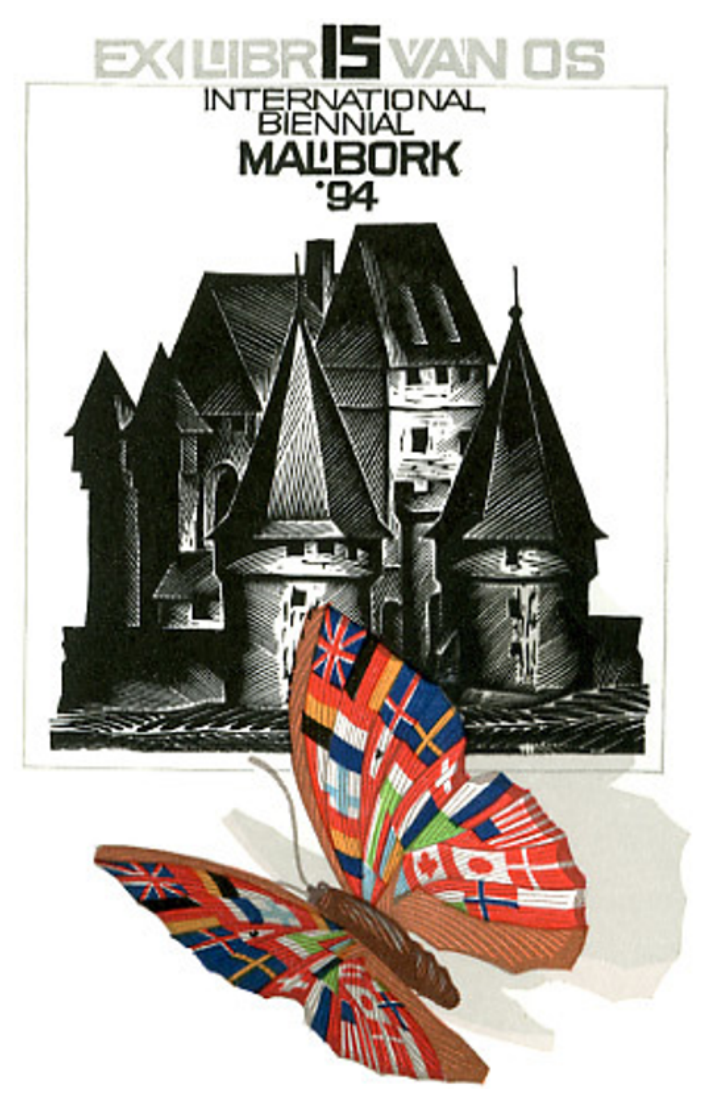

» Figure 4: Pugachevsky A. EL (P.) Van Os. X6/12. 1993

Gennady Pugachevsky, in spite of the fact he studied xylography under his father, has a different images style, more delicate, fragile, light, but his compositions performance level is high as well, if not to say it more strikes with scrupulousness and pinpoint precision. Greater sensitivity to the spirit of the time is the main thing that distinguishes Gennady's work from his father's artistic searches. There is not only ex-libris in the technique of plastic engraving but web-design, computer graphics, water colours, logo, graphic design, etc. in the artist's arsenal as well. Belonging to a younger generation has its impact. It should be noted the ex-libris itself, as well as the sheet of his prints (Figure 5), was also created by Gennady in the permanent xylography technique, more often in colour. Moreover, its polychromy sometimes 
reaches uniqueness - some compositions are printed from 15-17 boards. At the same time, the combination process during printing becomes almost inimitable and requires the highest level of technical skill (Figure 6). G. Pugachevsky's imagery is more sophisticated, refined, his oeuvre includes much more non-objective compositions, stylization reaches a high standard while there is a fine sense of humor in object compositions, although stylized, but more meaningful and close to naturalist representation in his father's works.

\section{Conclusions}

Kiev modern ex-libris school can rightly be considered one of the most universal: on the one hand, its representatives are trying to extend their technological experiments range to the maximum, working in techniques of both chalcography and xylography, having a tolerant attitude to innovations, trying their hand at computer graphic arts, synthesizing classical techniques tooling. But, on the other hand, it is the Kiev masters, who might make the most tangible contribution today to xylography academic, classical techniques preserving process, resorting to xylography to create a bookplate. And it is precisely because of the Kiev ex-libris school representatives Ukrainian wood and plastics engraving is known far beyond the bor-

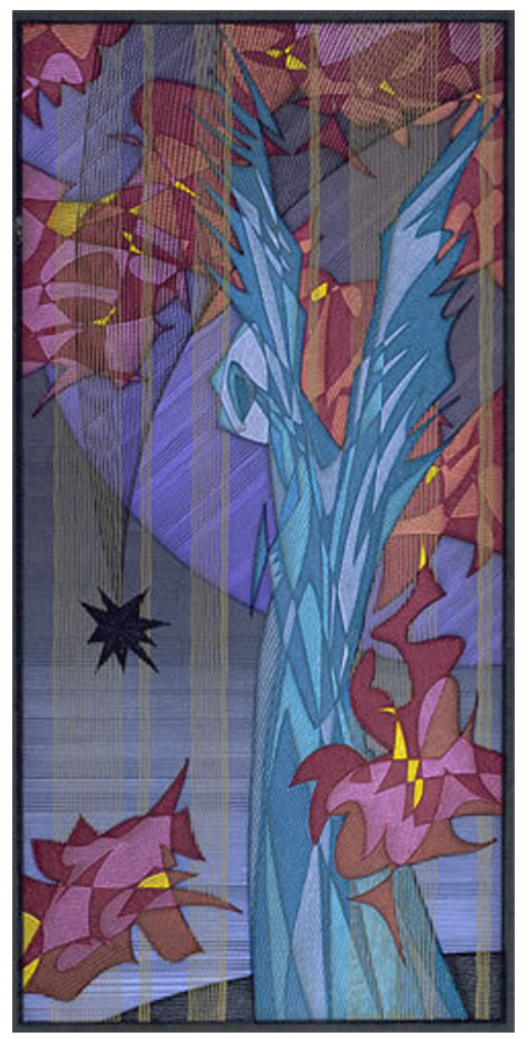

» Figure 5: Pugachevsky G. "Grief of blue Angel". X6. 1999 ders of the country, which became possible because of the intense exhibition and competition artists' activity, their mobility and readiness for the Ukrainian ex-libris presentation at a creative event of any level.

\section{References}

Berdychevsky, J. (1977) The art of ex libris [Mystetstvo exlibrisa]. Kiev, Advertising.

Kamenetskaya, Y. (2019) Contemporary Ukrainian ex-libris in the collection of the Frederikshavn Art Museum. East European Scientific Journal. 5 (45), 4-7.

Mikhalchuk, V. (2014b) Ex-libris as an object of collecting: the experience of modern Ukraine. Scientific aspect. 2, 92-10.

Mikhalchuk, V. (2014a) The main trends in the actualization of ex-libris on the contemporary world art market. Bulletin of the HDADM. 3, 70-75.

Nesterenko, P. (2002). Ukrainian Ex-Libris of the XVI-XX centuries. Conceptual foundations of development and periodization. Matherials for Ukrainian Art History. 1, 163-169.

Nesterenko, P. (2020) Ex-libris as an research on the history of Ukrainian culture, a complex of spiritual achievements of society. Art-platform. 2, 162-179.

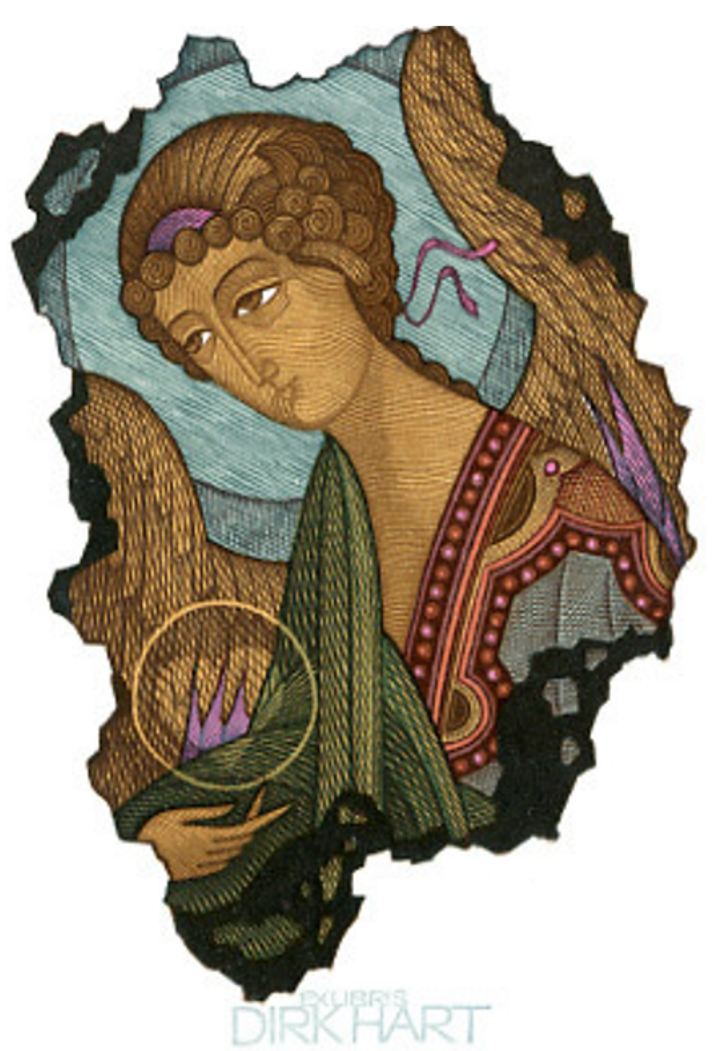

» Figure 6: Pugachevsky G. EL Dirk Hart. X6/6. 1995 
Romanenkova, J. (1999a) Graphic image of philosophy and mythology. Encyclopaedia Bio- Bibliographical of the Art of the Contemporary Ex-Libris. 24, 101-112.

Romanenkova, J. (1999b) By colour words about white ex-libris. Encyclopaedia Bio-Bibliographical of the Art of the Contemporary Ex-Libris. 24, 153-162.

Romanenkova, J. (2021) Bookplate in the artistic culture of Ukraine at the turn of the XX and XXI centuries. Text. Book. Book publishing. 25, 122-143.

Romanenkova, J., Bratus, I. \& Kuzmenko, H. (2021) Ukrainian Ex Libris at the End of the 20th Century and the beginning of the 21st century as an instrument of the intercultural dialogue. Agathos. 12 (22), 125-136.

Romanenkova, J., Bratus, I., Mikhalchuk, V. \& Gunka, A. (2021) Lvov ex-libris school as the traditions keeper of the intaglio printing techniques in the Ukrainian graphic arts at the turn of the XXth and XXIth centuries. Revista inclusiones. 8, 321-331.

Romanenkova, Y. (2003) Ukrainian ex-libris of the last third of the XX century in the worldcontext: the main evolutionary phases. In: $V$ scientific and technical conference "AVIA2003", 23-25 April 2003, Kiev, Ukraine. Kiev, NAU. pp. 102-105.

Romanenkova, Y. (2015a) Ex-libris as a method of taste forming in modern art space. In: Fourth Kazan art history Readings, 19-20 November 2015, Kazan, Tatarstan. Kazan, Zaman. pp. 67-69.

Romanenkova, Y. (2015b) Ukrainian ex-libris on the international arena of contemporary graphic arts. Art Criticism of Ukraine. 15, 111-118.

Safonova T. (2011) Informativeness of the Ex-Libris: aesthetic aspects. Herald of the National Academy of Culture and Arts Management. 1, 79-84.

Tupik, V. (2017) The role of Ukrainian ex-libris artists in shaping of the competitiveness of Ukrainian graphic arts in the international arena. Young scientist. 5 (45), 80-83.

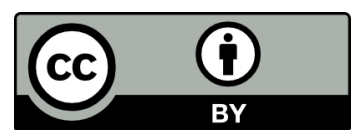

(C) 2021 Authors. Published by the University of Novi Sad, Faculty of Technical Sciences, Department of Graphic Engineering and Design. This article is an open access article distributed under the terms and conditions of the Creative Commons Attribution license 3.0 Serbia (http://creativecommons.org/licenses/by/3.0/rs/). 